\title{
Screening Donated Blood for Transfusion-Transmissible Cytomegalovirus Infection among Libyans
}

\author{
Farag Bleiblo1,2*, Abdelhakim Eljaki', Mohamed Bumadian', Khaled Elwaheishi', \\ Eman Almismary', Mabroka Aljlale', Rabea Alghazal'3, Mohammed Abraheem4 \\ ${ }^{1}$ Department of Microbiology, Faculty of Science, University of Benghazi, Benghazi, Libya \\ ${ }^{2}$ Department of Chemistry and Biochemistry and the Biomolecular Sciences Programme, Laurentian University, \\ Sudbury, Canada \\ ${ }^{3}$ Immunology \& Virology Laboratory, Benghazi Children Hospital, Benghazi, Libya \\ ${ }^{4}$ Department of Botany, Faculty of Arts and Science/Alkufra, University of Benghazi, Benghazi, Libya \\ Email: ${ }^{\star} \mathrm{x}$ _bleiblo@laurentian.ca
}

How to cite this paper: Bleiblo, F., Eljaki, A., Bumadian, M., Elwaheishi, K., Almismary, E., Aljlale, M., Alghazal, R. and Abraheem, M. (2020) Screening Donated Blood for Transfusion-Transmissible Cytomegalovirus Infection among Libyans. Journal of Biosciences and Medicines, 8, 5-12. https://doi.org/10.4236/jbm.2020.81002

Received: October 27, 2019

Accepted: December 21, 2019

Published: December 24, 2019

Copyright $\odot 2020$ by author(s) and Scientific Research Publishing Inc. This work is licensed under the Creative Commons Attribution International License (CC BY 4.0).

http://creativecommons.org/licenses/by/4.0/

\begin{abstract}
Human cytomegalovirus (HCMV) is a ubiquitous DNA-containing herpesvirus causes severe and fatal diseases in immunocompromised patients and a prevalent cause of virus-associated birth defects. Blood transfusion donated for neonates, pregnant women, and immunocompromised patients should be adequately screened for evidences of CMV infection prior to use in clinical management. The effective national programmes for quality-assured screening of donated blood have not yet been fully established, hence this study was undertaken to assess whether any bloodborne-CMV infections pose a significant threat to the safety of the blood supplies. A total of 200 voluntary blood donor subjects admitted to the Blood Bank of Benghazi/Libya were screened for transfusion-transmissible CMV (TT-CMV) using a highly sensitive CMV total IgG and IgM antibody enzyme immunoassay as well as CMV pp65 antigenemia assays. We determined that the overall seropositivity for IgG antibodies (80.50\%) was higher than that of IgM antibodies $(39.00 \%)$, but only $2(1.00 \%)$ individuals out of these donors were seropositive for the CMV-antigenic protein pp65. The frequency of CMV infection based on gender was incomparable due to the small population number of blood-donated females. According to age, there was not influence of various age groups on prevalence of anti-CMV IgG antibodies, while a progressive increase in seropositivity of CMV-IgM antibodies with age was detected. The age groups were not significantly associated with CMV prevalence. In contrast, only $2(1.00 \%)$ patients were shown to be positive for all three performed assays indicating a recurrent infection.
\end{abstract}


Our findings prove a risk of primary transfusion-associated transmission of CMV and may provide a policy guidance on ensuring safe blood supplies accessible to all patients who require transfusion.

\section{Keywords}

Cytomegalovirus, Seroprevalence, Blood Transfusion, Transfusion-Transmissible Cytomegalovirus, Enzyme Immunoassays

\section{Introduction}

Human cytomegalovirus (HCMV) is a ubiquitous virus infection distributed worldwide. This virus is the most common infectious cause of birth defects and congenital diseases, the most significant and difficult opportunistic pathogen affecting immunocompromised patients [1] [2]. HCMV infects an overwhelming majority of the population, transmitted efficiently throughout life and universally through contacts with bodily secretions. After the initial acquisition of HCMV, the virus replicates and causes a systemic infection, sometimes detected as a leukocyte-associated viremia, and disseminates to secretory organs such as salivary glands and kidney where replication produces virus found in secretions [3].Viruses may be shed in any body fluids, including urine, saliva, tears, semen, and cervical secretions, and persistent shedding may continue for months to years, depending on age and immune status of the host [3] [4]. Like other human herpesviruses, HCMV is never completely cleared and remains latent for the life of the host. Persistently and sporadically shed virus is an important recurrent source of virus for transmission. Susceptibility to HCMV disease is associated with a compromised immune system, particularly related to defects in cell-mediated CD4 and CD8 T-cell functions [2]. Despite potential antiviral drugs aimed to control the overall disease burden, the HCMV remains an important etiologic agent of opportunistic infections and disease in immunocompromised individuals following organ transplantation and hematopoietic cell allografting, immunosuppressive therapies, and genetic or acquired immunodeficiency [1] [2] [5].

During active infection, the HCMV circulates in leukocytes and plasma and subsequently persists latent in leucocytes and other body cells. Following reactivation, the virus released again in blood stream and readily transmitted by transfusion of contaminated blood. In population where CMV is highly prevalent, there is a higher risk for blood transfused by viremic donors. Thus, for the majority of countries, anti-CMV screening is still central to the prevention of posttransfusion CMV [6] [7]. Safe and effective blood transfusion requires several processes including testing donated blood samples for transfusion-transmissible infections (TTIs) to minimize the risk of transmitting infections to seronegative recipients. Therefore, this study aimed to screen donated blood for evidence of CMV infection prior to the release of blood for clinical use to establish an effec- 
tive national blood screening programme to protect the recipients of blood transfusion from TTIs CMV [6] [7].

\section{Materials and Methods}

\subsection{Patient Population}

Two hundred subjects admitted to the Blood Bank of Benghazi/Libya were recruited in this study. Informed consent was obtained from all patients and the protocol was approved by the Blood Services Ethics Committee. Demographic information including age, sex, marital status, literacy status, residential status, socioeconomic status were obtained by means of referring to medical records and personal interviews. Throughout their tenure on the Blood Unit, a $5 \mathrm{ml}$ of blood was drawn from donors by vein puncture and placed in plastic disposable tubes; it was left to stand at room temperature $\left(20^{\circ} \mathrm{C}-25^{\circ} \mathrm{C}\right)$ to allow for clotting, then the sera was separated by centrifugation 10,000 rpm for 5 minutes. Sera samples were stored at $-20^{\circ} \mathrm{C}$ and later tested for cytomegalovirus antibodies by serological investigation.

\subsection{Detection of CMV IgG}

Microplate-based enzyme-linked immunoassay (ELISA) was used for the qualitative and quantitative detection of anti-CMV IgG antibodies to cytomegalovirus in donors' sera according to the manufacturer's instructions (Autobio Diagnostics Co, LTD). The assay is based upon the two steps indirect enzyme immunoassay (EIA). Briefly, in the first step, sample and recombinant CMV coated microwells are combined. During the incubation, the anti-CMV antibodies present in the sample bind to the antigen coated in the wells. After the washing, in the second step enzyme-conjugate is added to the reaction mixture. The mouse anti-human IgG in the enzyme-conjugate is allowed to react with the anti-CMV IgG attached to the solid phase in the first step. Then, a complex is generated between the solid phase, the anti-CMV IgG within the sample, and the mouse anti-human IgG in the enzyme conjugate. Then, the substrate A and substrate B are added and catalyzed by this complex. The resulting chromogenic reaction is measured in absorbance. The intensity of color signals which reflects the amount of CMV IgG antibodies in the samples was measured with microplate reader at $450 / 630 \mathrm{~nm}$ were interpreted according to the manufacturer's instructions. Samples that have optical densities $10 \%$ below the cutoff were considered as negative whereas

\subsection{Detection of CMV IgM}

To determine if the blood donors have acute or primary infection, serum samples were assayed for CMV-specific IgM using a CMV IgM ELISA (Autobio Diagnostics Co., Ltd.) and the results were interpreted according to the manufacturer's instructions. Samples giving an absorbance less than the cut-off value were considered negative for the presence of CMV-specific IgM antibodies whe- 
reas those giving an absorbance equal to or greater than the cut-off value were considered reactively positive.

\subsection{Detection of CMV Antigenemia}

To quantitate the viral antigenemia, we performed Sandwich-ELISA to assay CMV lower matrix protein pp65 in donors' sera according to the manufacturer instructions (Sung long Biotech). The microtiter stripplate provided with this assay are precoated with antibodies specific to CMV pp65. Standards and samples were added to stripplate wells and combined to the specific antibody and then a horseradish CMV pp65 (HRP)-conjugate specific for CMV pp65 was added to each microelisa stripplate well and incubated. The TMB substrate solution was added to each after washing away the free components. The wells containing the CMV pp65 and HRP-conjugated CMV pp65 antibody appeared blue and then turned yellow after adding the stop solution. The optical density (OD) was measured by microtiter plate reader at $450 \mathrm{~nm}$. The concentration of CMV pp65 in the sample was calculated by comparing the OD of the sample to the standard curve according to the manufacturer instructions.

\section{Results and Discussion}

Two hundred subjects of blood donors were followed during the course of the study. Our results revealed that $161(80.50 \%)$ out of these subjects were seropositive for CMV-IgG indicating a past exposure to infection, while 78 (39.00\%) individuals were seropositive for CMV-IgM indicating a recent or primary infection (Table 1). Based on the laboratory diagnosis of CMV-pp65, we determined that only $2(1.00 \%)$ donors had CMV viremia. These two donors were shown to be positive for all three performed assays indicated the presence of recurrent infection.

Cytomegalovirus is considered as one of the most encountered opportunistic viral pathogens distributed universally among human population affecting particularly immunocompromised patients. Several epidemiological studies on seroprevalence of HCMV infection in blood donors has been reported. It seems that the prevalence of CMV-IgG antibodies among blood donors varies according to the national infection rates of the general population and the socioeconomic characteristics of the blood donors. In agreement with our findings, several studies conducted in different regions of India showed a significantly high CMV seropositivity among blood donors population ranged between $90 \%$ and 100\% [8] [9] [10] [11]. The different contributing factors for high seroprevalence

Table 1. Prevalence of CMV-IgG, CMV-IgM, and CMV-pp65 Antibodies in Blood Donors.

\begin{tabular}{ccccccc}
\hline \multirow{2}{*}{$\begin{array}{c}\text { Total No. } \\
\text { of Patients }\end{array}$} & \multicolumn{2}{c}{ CMV-IgG } & \multicolumn{2}{c}{ CMV-IgM } & \multicolumn{2}{c}{ CMV-pp65 } \\
\cline { 2 - 7 } & No & $\%$ & No & $\%$ & No & $\%$ \\
\hline 200 & 161 & 80.50 & 78 & 39.00 & 2 & 1.00 \\
\hline
\end{tabular}


may be related to low socioeconomic status and closeness of contact within population, environmental factors and climatic conditions. The overall seroprevalence of CMV among Japanese blood donors was $76.6 \%$ and the CMV DNA was detected in the cellular fraction of some donors [12]. In Nigeria, prevalence of anti-CMV IgG antibodies was $96.2 \%$ and that of IgM was $2.6 \%$ [13]. In a German study, the seroprevalence of CMV among blood donors ranged from 30\% and increased up to about $80 \%$ in donors older than 65 years [14]. However, young donors already had a distinctly higher seroprevalence (about $70 \%$ ) in Australia than was reported for Europe or North America [15]. Ethnicity has been suggested also to be an important factor for CMV seroprevalence. Low rates are reported for non-Hispanic Whites (about 50\%) and very high rates for South Asians ( $\sim 89 \%$ of South Asian UK-born women and 98\% among women born in South Asia and living in the UK) [16]. IgM appears first in response to a CMV primary infection CMV or reactivations. In general, IgM antibodies might be detectable both prior to IgG antibodies or shortly after IgG seroconversion and remain positive for several months [17]. Studies on the IgM seroprevalence in blood donors are less frequent than those about IgG seroprevalence. Most studies reported that IgM seroprevalence is much lower comparing to that of IgG [12]. In this study, we could not compare the overall seropositivity of CMV according to gender because the female participants of voluntary blood donors were very small. However, several lines of evidence including both genders consistently reported prevalence rates that are slightly higher in women than in men. Population-based evaluation of HCMV prevalence that have been derived from the National Health and Nutrition Examination Survey (NHANES), starting with a 1988 to 1994 set and continuing with 1999 to 2004 set (6 years of age or older) estimated that more female patients (63.5\%) than male (54.1\%) were infected [18] [19]. According to the age-related prevalence of CMV infection, the rates of CMV-IgG antibodies was detected to be comparable in different age groups that have been investigated except for the people within $\geq 60$ years where there was no infection detected (Table 2). Regarding the IgM seropositivity, we found that the age group within 45 - 59 years of old had the highest rate (51.28\%) followed by those within the age group 30 - 44 years (39.80\%). The CMV-pp65

Table 2. Distribution of CMV-IgG, CMV-IgM, and CMV-pp65 antibodies according to age groups.

\begin{tabular}{|c|c|c|c|c|c|c|c|}
\hline \multirow{2}{*}{$\begin{array}{l}\text { Age } \\
\text { Group }\end{array}$} & \multirow{2}{*}{$\begin{array}{c}\text { No. of } \\
\text { Patients }\end{array}$} & \multicolumn{2}{|c|}{ CMV-IgG } & \multicolumn{2}{|c|}{ CMV-IgM } & \multicolumn{2}{|c|}{ CMV-pp65 } \\
\hline & & No & $\%$ & No & $\%$ & No & $\%$ \\
\hline$<30$ & 52 & 43 & 82.69 & 16 & 30.76 & 1 & 1.92 \\
\hline $30-44$ & 103 & 85 & 82.52 & 41 & 39.80 & 1 & 0.97 \\
\hline $45-59$ & 39 & 32 & 84.61 & 20 & 51.28 & 0 & 0 \\
\hline$\geq 60$ & 6 & 0 & 0 & 1 & 16.66 & 0 & 0 \\
\hline Total & 200 & 160 & 80.50 & 78 & 39.00 & 2 & 1.00 \\
\hline \multicolumn{2}{|c|}{$P$} & \multicolumn{2}{|c|}{$>0.05$} & \multicolumn{2}{|c|}{$>0.05$} & \multicolumn{2}{|c|}{$>0.05$} \\
\hline
\end{tabular}


positivity rate was determined to be higher within the age group younger than 30 years (1.92\%). Although, CMV seroprevalence did not differ significantly between age groups $(\mathrm{p}>0.05)$.

Although the prevalence of CMV infection increases with age in many age groups that have been studied, the overall prevalence of infection and the age vary greatly according to living circumstances and socioeconomic status based on personal interview. In general, prevalence of infection is greater, and virus is acquired earlier in life in developing countries compared to the United States and Europe, where prevalence is greater in the lower socioeconomic strata, among nonwhites, and in immigrant populations from developing countries [20] [21]. Based on a large samplings study derived from NHANES, it has been shown that the overall age-adjusted prevalence of HCMV infection in the United States remains about 59\%, with about one-half of the U.S. population aged 6 to 49 infected [18] [19]. This study reported that the age-related prevalence of HCMV infection was greater within groups aged greater than 30 years. It has been demonstrated that the seroprevalence of blood donors aged between 18 and 30 years was about $30 \%$ and increased gradually up to about $80 \%$ in German donors older than 65 years [14]. Similarly, older donors also had an increased seroprevalence among Australian populations. However, young donors already had a distinctly higher seroprevalence in Brazil and Australia than was reported for Europe or North America [15] [22].

\section{Conclusion}

Based on these findings, we highly recommend a quality-assured screening of all donated blood for transfusion transmissible infections, including CMV to establish effective national programmes to easily prevent the unacceptable risk of acquiring life-threatening diseases.

\section{Conflicts of Interest}

The authors declare no conflicts of interest regarding the publication of this paper.

\section{References}

[1] Cannon, M.J., Schmid, D.S. and Hyde, T.B. (2010) Review of Cytomegalovirus Seroprevalence and Demographic Characteristics Associated with Infection. Reviews in Medical Virology, 20, 202-213. https://doi.org/10.1002/rmv.655

[2] Mocarski, E.S., Shenk, Griffiths, P.D. and Pass, R.F. (2013) Cytomegaloviruses. In: Knipe, D.M. and Howley, P.M., Eds., Field Virology, 6th Edition, Lippincott Williams \& Wilkin, Philadelphia, 1960-2014.

[3] Brooks, G.F., Carroll, K.C., Butel, J.S., Morse, S.A. and Mietzner, T.A. (2010) Jawetz, Melnick and Adelberg's Medical Microbiology. 25th Edition, McGraw-Hill Companies Inc., New York, 467-488.

[4] Trkulic, M., Jovanovic, D., Ostojic, G., Kovacevic, Z. and Taseski, J. (2000) Cytomegalovirus Infection in Patients with Kidney Diseases. Vojnosanitetski Pregled, 


\section{7, 63-67.}

[5] Cavlek, T., Kolaric, B., Sternak, S., Kos, M., Kaic, B. and Galinovic, G. (2015) Prevalence and Dynamics of Cytomegalovirus Infection among Patients Undergoing Chronic Hemodialysis. Indian Journal of Nephrology, 25, 95-98. https://doi.org/10.4103/0971-4065.139488

[6] van Prooijen, H.C., Visser, J.J., van Oostendorp, W.R., de Gast, G.C. and Verdonck, L.F. (1994) Prevention of Primary Transfusion-Associated Cytomegalovirus Infection in Bone Marrow Transplant Recipients by the Removal of White Cells from Blood Components with High-Affinity Filters. British Journal of Haematology, 87, 144-147. https://doi.org/10.1111/j.1365-2141.1994.tb04884.x

[7] Roback, J.D. (2002) CMV and Blood Transfusions. Reviews in Medical Virology, 12, 211-219. https://doi.org/10.1002/rmv.353

[8] Kothari, A., Ramachandran, V.G., Gupta, P., Singh, B. and Talwar, V. (2011) Seroprevalence of Cytomegalovirus among Voluntary Blood Donors in Delhi India. Journal of Health, Population and Nutrition, 20, 348-351.

[9] Pal, S.R., Chitkara, N.L. and Krech, U. (1972) Sero-Epidemiology of Cytomegalovirus Infection in and around Chandigarh (Northern India). Indian Journal of Medical Research, 60, 973-978.

[10] Madhavan, H.N., Prakash, K. and Agarwal, S.C. (1974) Cytomegalovirus Infection in Pondicherry (South India) - A Serological Survey. Indian Journal of Medical Research, 62, 297-300.

[11] Mukundan, P., Jadhav, M. and John, T.J. (1977) Prevalence of Cytomegalovirus Antibody in Young Children in Vellore. Indian Journal of Medical Research, 65, 589592.

[12] Furui, Y., Satake, M., Hoshi, Y., Uchida, S., Suzuki, K. and Tadokoro, K. (2013) Cytomegalovirus (CMV) Seroprevalence in Japanese Blood Donors and High Detection Frequency of CMV DNA in Elderly Donors. Transfusion, 53, 2190-2197. https://doi.org/10.1111/trf.12390

[13] Bawa, M.K., Mamman, A., Olayinka, A., Gidado, S., Waziri, N.E., Balogun, M.S., Getso, K.I., Dalhat, M.M., Nsubuga, P., Aliyu, N., Bala, H., Muhammad, H., Haladu, S., Shehu, U.L. and Nguku, P.M. (2019) Blood Donor Safety, Prevalence and Associated Factors for Cytomegalovirus Infection among Blood Donors in Minna-Nigeria, 2014. The Pan African Medical Journal, 32, 1-6. https://doi.org/10.11604/pamj.supp.2019.32.1.13297

[14] Hecker, M., Qiu, D., Marquardt, K., Bein, G. and Hackstein, H. (2004) Continuous Cytomegalovirus Seroconversion in a Large Group of Healthy Blood Donors. Vox Sanguinis, 86, 41-44. https://doi.org/10.1111/j.0042-9007.2004.00388.x

[15] Lancini, D.V., Faddy, H.M., Ismay, S., Chesneau, S., Hogan, C. and Flower, R.L. (2016) Cytomegalovirus in Australian Blood Donors: Seroepidemiologic and Seronegative Red Blood Cell Component Inventories. Transfusion, 56, 1616-1621. https://doi.org/10.1111/trf.13459

[16] Pembrey, L., Raynor, P., Griffiths, P., Chaytor, S., Wright, J. and Hall, A.J. (2013) Seroprevalence of Cytomegalovirus, Epstein Barr Virus and Varicella Zoster Virus among Pregnant Women in Bradford: A Cohort Study. PLoS ONE, 8, e81881. https://doi.org/10.1371/journal.pone.0081881

[17] Ziemann, M., Unmack, A., Steppat, D., Juhl, D., Görg, S. and Hennig, H. (2010) The natural Course of Primary Cytomegalovirus Infection in Blood Donors. Vox Sanguinis, 99, 24-33. https://doi.org/10.1111/j.1423-0410.2009.01306.x

[18] Bate, S.L., Dollard, S.C. and Cannon, M.J. (2010) Cytomegalovirus Seroprevalence 
in the United States: The National Health and Nutrition Examination Surveys, 19882004. Clinical Infectious Diseases, 50, 1439-1447. https://doi.org/10.1086/652438

[19] Staras, S.A., Dollard, S.C. and Radford, K.W. (2006) Seroprevalence of Cytomegalovirus Infection in the United States, 1988-1994. Clinical Infectious Diseases, 43, 1143-1151. https://doi.org/10.1086/508173

[20] Grifiths, P.D. and Baboonian, C.A. (1984) Prospective Study of Primary Cytomegalovirus Infection during Pregnancy: Final Report. BJOG, 91, 307-315. https://doi.org/10.1111/j.1471-0528.1984.tb05915.x

[21] Stadler, L.P., Bernstein, D.I. and Callahan, S.T. (2010) Seroprevalence of Cytomegalovirus (CMV) and Risk Factors for Infection in Adolescent Males. Clinical Infectious Diseases, 51, 76-81. https://doi.org/10.1086/656918

[22] Souza, M.A., Passos, A.M., Treitinger, A. and Spada, C. (2010) Seroprevalence of Cytomegalovirus Antibodies in Blood Donors in Southern, Brazil. Revista da Sociedade Brasileira de Medicina Tropical, 43, 359-361.

https://doi.org/10.1590/S0037-86822010000400004 